\title{
LEFT VENTRICULAR DIASTOLIC DYSFUNCTION AND OXYGEN SUPPLY OF LOWER EXTREMITIES IN PATIENTS WITH STABLE ISCHEMIC HEART DISEASE AND CONCOMITANT TYPE 2 DIABETES MELLITUS
}

\author{
N. I. Yarema, N. V. Pasechko, A. I. Khomitska, I. P. Savchenko, \\ I. V. Smachylo, L. V. Naumova, L. V. Radetska, A. O. Bob, \\ M. E. Havrylyuk, O. O. Bob, N. M. Havrylyuk, O. I. Kotsyuba \\ I. HORBACHEVSKY TERNOPIL STATE MEDICAL UNIVERSITY, TERNOPIL, UKRAINE
}

\begin{abstract}
Background. The peculiarities of diastolic heart failure and indices of arterial and venous blood oxygenation in patients with stable ischemic heart disease and concomitant type 2 diabetes mellitus are presented in the article. Obvious left ventricular diastolic dysfunction with the increased levels of natriuretic peptide, uric acid and decreased indices of arterial and venous blood oxygenation in the presence of comorbid type 2 diabetes mellitus have been revealed.

Objective. The research was aimed to study the peculiarities of left ventricular diastolic function disorders, levels of NT-proBNP, uric acid and indices of arterial and venous blood oxygenation in patients suffering from stable exertional angina with underlying comorbid type 2 diabetes mellitus.

Methods. 70 patients with IHD: stable exertional angina of the III functional class, were examined. The first group comprised 39 patients with stable exertional angina of the III functional class with left ventricular diastolic dysfunction; the second group - 31 patients with stable exertional angina of the III functional class with left ventricular diastolic dysfunction and concomitant type 2 diabetes mellitus. All the examined patients underwent $B D$ - echocardioscopy, with the detailed evaluation of left ventricular diastolic function, NT-proBNP and uric acid levels in venous blood were determined by immunoenzyme method, indices of arterial and venous blood oxygenation were evaluated too.
\end{abstract}

Results. The correlation between left ventricle diastolic function and oxygen volume consumed by the tissues of lower extremities in patients with stable ischemic heart disease and concomitant type 2 diabetes mellitus was determined.

Conclusions. In patients with stable IHD, left ventricular diastolic dysfunction and concomitant type 2 diabetes mellitus the levels of NT-proBNP, uric acid and oxygen supply of lower extremities are significantly higher as compared to patients with IHD without type 2 diabetes mellitus.

KEY WORDS: stable ischemic heart disease; left ventricular diastolic dysfunction; diabetes mellitus; natriuretic peptide; blood oxygenation.

\section{Introduction}

Stable ischemic heart disease (IHD) in patients with type 2 diabetes mellitus is diagnosed in 2-4 times more often than in people of the same age without diabetes [1]. According to some authors, diabetes mellitus negatively influences on left ventricular diastolic function, and the increase of diabetes mellitus duration is accompanied by chronic heart failure development [4]. There are some findings that left ventricular diastolic dysfunction may be caused by diabetes mellitus development regardless

Corresponding author: Alla Khomitska, Department of Internal Medicine №1, I. Horbachevsky Ternopil State Medical University, 1 Clinichna Street, Ternopil, Ukraine, 282004

Phone number: +0976860500

E-mail: balabanai@tdmu.edu.ua of the presence of IHD or arterial hypertension [2]. The results of some researches show that the prevalence of asymptomatic left ventricular diastolic dysfunction in patients with type 2 diabetes mellitus is $63.2 \%$ and increases with age [4]. One of the main markers of chronic heart failure is $\mathrm{N}$-terminal brain natriuretic propeptide (NT-proBNP), its levels increase as chronic heart failure develops [3]. An asymptomatic hyperuricemia is also an important risk factor in the development of cardiovascular complications. Therefore early diagnostic of this pathology is important for proper drug-induced correction in patients with IHD, left ventricular diastolic dysfunction and concomitant type 2 diabetes mellitus [5]. 
The research was aimed to study the peculiarities of left ventricular diastolic dysfunction, the levels of NT-proBNP, uric acid and indices of arterial and venous blood oxygenation in patients with stable exertional angina with comorbid type 2 diabetes mellitus.

\section{Methods}

70 patients with IHD: stable exertional angina of the III functional class, were examined. The average age of the examined patients was $(58.38 \pm 0.64)$ years old. The first group comprised 39 patients suffering from stable exertional angina of the III functional class with left ventricular diastolic dysfunction; the second group counted in 31 patients with stable exertional angina of the III functional class with left ventricular diastolic dysfunction and concomitant type 2 diabetes mellitus. All patients were diagnosed with relaxation type of left ventricular diastolic dysfunction, and left ventricular ejection fraction in all examined patients was higher than $45 \%$, which means that systolic function of the left ventricle was preserved. The control group comprised 20 healthy individuals of the same age and sex. All the examined patients underwent BD-echocardioscopy with the detailed evaluation of left ventricular diastolic function, NT-proBNP and uric acid levels in venous blood were determined by immunoenzyme method, indices of arterial and venous blood oxygenation were evaluated too (saturation of arterial $\left(\mathrm{Sa}_{0} \mathrm{O}_{2}\right)$ and venous $\left(\mathrm{Sv} \mathrm{O}_{2}\right)$ ) blood - with pulse oximeter; arterial $\left(\mathrm{Ca}^{\circ} \mathrm{O}_{2}\right)$ and venous $\left(\mathrm{Cv} \mathrm{O}_{2}\right)$ blood oxygenation in vitro including the assessment of oxygen volume consumed by the tissues of lower extremities Da. $\mathrm{O}_{2}$-Dv. $\mathrm{O}_{2}$ ) - with Oximeter Unistat apparatus (USA).

All statistical analyses were performed with Statistica 6.0 and Microsoft Excel. Data are expressed as means \pm standard deviation or as number (\%). Continuous variables were analyzed by the Student's t-test and the Mann-Whitney test. $\mathrm{P}<0.05$ was considered statistically significant. The authors had full access to information and take full responsibility for the integrity of the data. All authors have read and agreed to the manuscript as written. Institutional review committee approval and informed consents were obtained.

\section{Results}

In patients with IHD and concomitant type

2 diabetes mellitus correlation of E/A was by $34.8 \%(p<0.01)$ lower than in the control group and by $15.1 \%(p<0.05)$ higher than in patients with IHD without concomitant type 2 diabetes mellitus (Table 1). IVRT and DT values also differed considerably in patients with IHD, left ventricular diastolic dysfunction and concomitant type 2 diabetes mellitus, specifically: DT value was by $30.5 \%(p<0.01)$ higher than in the control group and by $24.1 \%(p<0.05)$ higher than in patients with IHD without type 2 diabetes mellitus. E' value was by $50.5 \%(p<0.01)$ lower in the $2^{\text {nd }}$ group of patients as compared to the control group, and by $26.8 \%(p<0.05)$ lower than in patients with IHD without type 2 diabetes mellitus. In patients with stable IHD correlation of $E / E$ ' was increasing to $(9.83 \pm 0.14)$ because of significant decrease in $\mathrm{E}^{\prime}$ and was in 1.8 times higher than in the control group and by $25.9 \%(p<0.01)$ higher as compared to the patients with IHD without type 2 diabetes mellitus that proves an increased inflexibility of myocardium in patients with comorbidity of IHD and type 2 diabetes mellitus.

NT-proBNP value in patients with stable IHD and concomitant type 2 diabetes mellitus was $(566.07 \pm 22.01) \mathrm{pg} / \mathrm{ml}$ and was by $35.6 \%(\mathrm{p}<0.01)$ higher as compared to the first group of the examined patients and by $78.7 \%(p<0.01)$ higher as compared to the control group that evidences more significant chronic heart failure development in patients with stable IHD and concomitant type 2 diabetes mellitus (Fig. 1).

In patients with IHD, left ventricular diastolic dysfunction and concomitant type 2 diabetes mellitus the level of uric acid was by $53.3 \%$ $(p<0.01)$ higher as compared to the control group and by $21.3 \%(p<0.05)$ higher as compared to the examined patients without con-

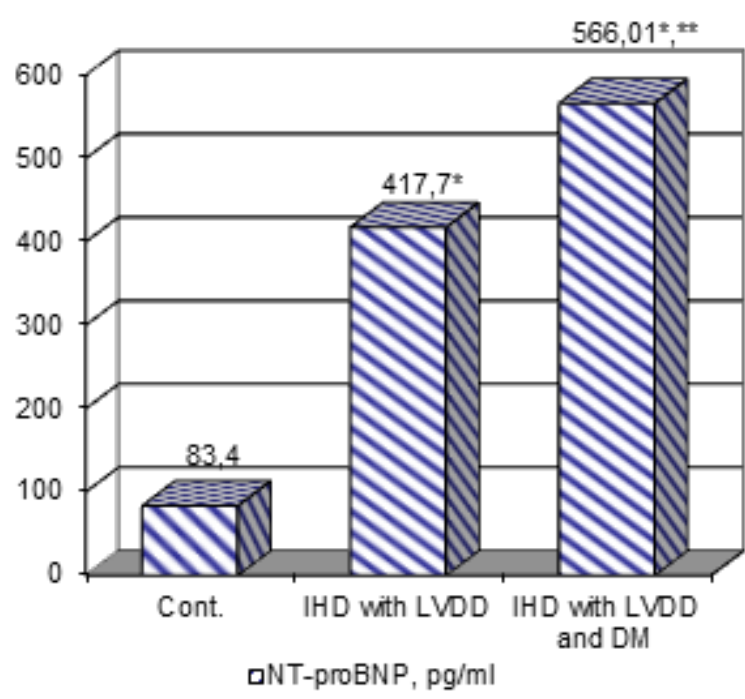

Fig. 1. Level of NT-proBNP in the examined patients 
comitant type 2 diabetes mellitus. The data obtained in our research confirm the results of some authors that hyperuricemia is an independent risk factor in the development of cardiovascular complications in patients with IHD and has negative effect on the clinical course of chronic heart failure.

In patients with stable exertional angina and concomitant type 2 diabetes mellitus the decrease in arterial and venous blood oxygenation indices as compared to the patients with stable IHD without type 2 diabetes mellitus was determined (Table 2). Sa. $\mathrm{O}_{2}$ was slightly lower in the $2^{\text {nd }}$ group than in the $1^{\text {st }}$ group. Sv. $\mathrm{O}_{2}$ value in the 2 group of patients with comorbid type 2 diabetes mellitus was by $21.8 \%(p<0.05)$ lower as compared to the patients of the $1^{\text {st }}$ group. $\mathrm{Ca} . \mathrm{O}_{2}$ and $\mathrm{Cv} . \mathrm{O}_{2}$ values were considerably lower in patients with left ventricular diastolic dysfunction and type 2 diabetes mellitus as compared to the patients without diabetes mellitus, respectively by $21.2 \%(p<0.01)$ and $18.5 \%(p<0.01)$, which indicates the deficiency of oxygen saturation of lower extremities tissues as the result of transvenous and transcapillary blood flow difficulties.
The volume of oxygen consumed by tissues of lower extremities $\mathrm{Da} . \mathrm{O}_{2}-\mathrm{Dv} . \mathrm{O}_{2}$ in patients with stable IHD and type 2 diabetes mellitus was $(44.85 \pm 0.94) \mathrm{ml} \cdot \mathrm{l}^{-1}$ and was by $9.6 \%(\mathrm{p}<0.05)$ lower as compared to the patients without type 2 diabetes mellitus. So, in patients with stable IHD and concomitant type 2 diabetes mellitus the decrease in oxygen volume, which is transported to the tissues of lower extremities, was accompanied by the decrease in oxygen volume consumed by the tissues of lower extremities.

The direct correlation between the decrease in value of E' decline and decrease oxygen volume consumed by the tissues of lower extremities in patients with stable ischemic heart disease and concomitant type 2 diabetes mellitus was revealed.

\section{Discussion}

According to the recent literature [6,8], violation of oxygen transporting processes of in the organism is predefined by insufficiency of pumping function of myocardium, by deceleration of blood stream in the vessels of greater circulation, by uneven distribution of blood in the system of microcirculation [7].

Table 1. Rates of left ventricular diastolic function in patients with IHD and concomitant type 2 diabetes mellitus

\begin{tabular}{|c|c|c|c|c|}
\hline Index & $\begin{array}{c}\text { Control group, } \\
\mathrm{n}=20\end{array}$ & $\begin{array}{c}\text { Group 1, } \\
\mathrm{n}=39\end{array}$ & $\begin{array}{c}\text { Group 2, } \\
\mathrm{n}=31\end{array}$ & $\mathrm{p}_{1-2}$ \\
\hline $\mathrm{E}, \mathrm{sm} / \mathrm{sec}$ & $0.72 \pm 0.01$ & $0.62 \pm 0.02^{*}$ & $0.56 \pm 0.02 *$ & $\mathrm{p}_{1-2}<0.05$ \\
\hline $\mathrm{A}, \mathrm{sm} / \mathrm{sec}$ & $0.54 \pm 0.03$ & $0.65 \pm 0.04^{*}$ & $0.70 \pm 0.03^{*}$ & $\mathrm{p}_{1-2}>0.05$ \\
\hline $\mathrm{E} / \mathrm{A}$ & $1.21 \pm 0.04$ & $0.93 \pm 0.05^{*}$ & $0.79 \pm 0.04^{*}$ & $\mathrm{p}_{1-2}<0.05$ \\
\hline $\mathrm{E}^{\prime}, \mathrm{sm} / \mathrm{sec}$ & $0.121 \pm 0.010$ & $0.082 \pm 0.007^{*}$ & $0.060 \pm 0.006^{*}$ & $\mathrm{p}_{1-2}<0.05$ \\
\hline E/E' & $5.34 \pm 0.18$ & $7.81 \pm 0.12^{*}$ & $9.83 \pm 0.14^{*}$ & $\mathrm{p}_{1-2}<0.01$ \\
\hline $\mathrm{DT}, \mathrm{msec}$ & $172.12 \pm 3.02$ & $181.26 \pm 5.23^{*}$ & $224.76 \pm 13.62^{*}$ & $\mathrm{p}_{1-2}<0.05$ \\
\hline IVRT, msec & $80.14 \pm 1.32$ & $98,04 \pm 4,25^{*}$ & $112.61 \pm 3.62 *$ & $\mathrm{p}_{1-2}<0.05$ \\
\hline
\end{tabular}

Notes: 1. * - significant differences of indices in comparison with the control;

2. $p_{1-2}$ - significant differences of indices between two groups of patients.

Table 2. Rates of arterial and venous blood oxygenation in patients with stable IHD, left ventricular diastolic dysfunction and type 2 diabetes mellitus

\begin{tabular}{|c|c|c|c|c|}
\hline Index & $\begin{array}{c}\text { Control group, } \\
n=20\end{array}$ & $\begin{array}{l}1 \text { group, } \\
n=39\end{array}$ & 2 group, & $p_{1-2}$ \\
\hline $\mathrm{Sa} \mathrm{O}_{2}, \%$ & $99.10 \pm 0.41$ & $96.12 \pm 0.74$ * & $91.53 \pm 0.51$ * & $p_{1-2}<0.05$ \\
\hline Sv. ${ }_{2}, \%$ & $70.31 \pm 0.33$ & $67.26 \pm 0.41$ * & $52.64 \pm 0.58 *$ & $p_{1-2}<0.01$ \\
\hline $\mathrm{Ca} . \mathrm{O}_{2}, \mathrm{ml} \cdot \mathrm{l}^{-1}$ & $149.20 \pm 0.62$ & $142.10 \pm 1.53^{*}$ & $112.57 \pm 2.65 *$ & $p_{1-2}<0.01$ \\
\hline $\mathrm{Cv} . \mathrm{O}_{2^{\prime}} \mathrm{ml \cdot l^{-1 }}$ & $98.33 \pm 0.62$ & $94.14 \pm 1.41 *$ & $76.75 \pm 2.57 *$ & $\mathrm{p}_{1-2}<0.01$ \\
\hline Da. $\mathrm{O}_{2}-\mathrm{Dv} . \mathrm{O}_{2}, \mathrm{ml} \cdot \mathrm{l}^{-1}$ & $50.96 \pm 0.66$ & $47.91 \pm 0.62 *$ & $43.85 \pm 0.94 *$ & $\mathrm{p}_{1-2}<0.05$ \\
\hline
\end{tabular}

Notes: 1. * - significant differences of indices in comparison with the control,

2. $p_{1-2}$ - significant differences of indices between two groups of patients. 
For patients with stable IHD the circulatory hypoxia is of systemic nature, develops in the presence of chronic heart failure and develops in comorbid states [4, 7], type 2 diabetes mellitus in particular. It was established that in efficiency of oxygen transporting to the tissues of the organism, a functional ability of cardiovascular system is crucial [8], and that is why a search for effective methods of comorbid states treatment is a topical issue.

\section{Conclusions}

In the examined patients with stable IHD and concomitant type 2 diabetes mellitus more severe impairment of left ventricular diastolic function and the increase of its rigidity, caused by type 2 diabetes mellitus, were revealed.
In patients with stable IHD, left ventricular diastolic dysfunction and concomitant type 2 diabetes mellitus the levels of NT-proBNP and uric acid were significantly higher as compared to the patients with IHD without type 2 diabetes mellitus, which means that comorbidity with diabetes mellitus was the reason for more severe diastolic heart failure.

In patients with stable exertional angina and concomitant type 2 diabetes mellitus there was obvious oxygen deficiency in peripheral tissues with the decrease in oxygen volume consumed by the tissues of lower extremities, which worsens the course of chronic heart failure.

\section{References}

1. Arques S. Current clinical applications of spectral Tissue Doppler echocardiography as a noninvasive surrogate for left ventricular diastolic pressures is the diagnosis of heart failure with preserved left ventricular systolic function. Cardiovascular Ultrasound. 2007;5:28-16.

2. Danzmann LC. Left atrioventricular remodeling in the assessment of the left ventricle diastolic function in patients with heart failure: a review of the currently studied echocardiographic variables. Cardiovascular Ultrasound. 2008;6:69-56.

3. Exiara T. Left ventricular diastolic dysfunction in diabetes mellitus type 2. Hypertension. 2010;28: 294-289.

4. Galderisi M. Diastolic dysfunction and diabetic cardiomyopathy: evaluation by Doppler echo- cardiography. Journal American College Cardiology. 2006;48:1551-1548.

5. Koh M. Management of stable coronary artery disease. European Heart Journal. 2013;38:29492300.

6. Kovakenko VM. Stable ischemic heart disease. Reccomendations of Association of Cardiologists of Ukraine. 2016;1:176-1.

7. Roe MT. Patterns and prognostic implications of blood oxigention in patients with ischemic heart disease. European Heart Journal. 2014;29:24882480.

8. Owan TE. Trends in prevalence and outcome of heart failure with preserved ejection fraction. National England Journal of Medicine. 2012;355: 254-251. 